\title{
AS OITO VIAGENS \\ DE GUSTAVO PIQUEIRA \\ DESLOCAMENTO NO ESPAÇO E NO TEMPO
}

Marisa Midori Deaecto 
RESUMO Ressaltando discrepâncias e consequências para o público leitor da época e para as gerações futuras, a autora discute o impacto das histórias presentes na caixa Oito Viagens ao Brasil, de Gustavo Piqueira, na qual diferentes autores registram suas versões/interpretações/projeções a respeito das viagens realizadas no processo de conquista do Novo Mundo e os interesses do Velho Mundo pelas civilizações americanas. Além disso, relaciona esses registros com outras obras pertencentes ao contexto da história das descobertas como a de Hans Staden e Rabelais e destaca aspectos gráficos e editoriais explorados tanto na obra de Piqueira quanto nos relatos existentes nela.

CONQUISTA DA AMÉRICA •

NOVO MUNDO • CIVILIZAÇÕES

AMERICANAS.
THE EIGHT TRAVELS OF GUSTAVO PIQUEIRA:

DISPLACEMENT IN TIME AND SPACE

ABSTRACT Emphasizing discrepancies and consequences to target readers of that time and future generations, the author discusses the impact of the histories inside the box Oito Viagens ao Brasil, produced by Gustavo Piqueira. In this work, different authors record their versions/interpretations/ projections regarding the travelling done on the conquest of the New World, and the Old World's interests in the American civilizations. Additionally, the author connects those registers with other works present in the context of the history of discoveries, like Hans Staden and Rabelais' works. The author highlights the graphic and editorial aspects in Piqueira's box and the registers in it. CONQUEST OF AMERICA • NEW WORLD • AMERICA CIVILIZATIONS.

\section{SOBRE A AUTORA}

Marisa Midori Deaecto é professora do Departamento de Jornalismo e Editoração da Escola de Comunicações e Artes da Universidade de São Paulo (ECA-USP). Lecionou, como professora convidada, na École Natinale de Chartes, na École Normale Supérieure (Paris, rue D’Ulm) e na École Pratique des Hautes Études, na Cátedra de História e Civilização do Livro. Dedica-se a pesquisas sobre Economia e Cultura Urbana, tendo publicado livros e artigos voltados para essa temática. Editora da revista Livro (Revista do Núcleo de Estudos do Livro e da Edição-USP) e autora do blog Bibliomania (http://bibliomania-divercidades.blogspot.com.br/). 
História Verídica e Descrição de uma Terra de Selvagens, Nus e Cruéis Comedores de Seres Humanos, Situada no Novo Mundo da América, Desconhecida Antes e Depois de Jesus Cristo nas Terras de Hessen até os Dois Últimos Anos, Visto que Hans Staden, de Homberg, em Hessen, a Conheceu por Experiência Própria, e que Agora Traz a Público com Essa Impressão. Nesse longo título, o autor resume bem seu juízo sobre os povos que encontrou no Novo Mundo, "uma terra de selvagens, nus e cruéis comedores de seres humanos". Impressão que não seria registrada sem consequências para os leitores daqueles tempos distantes, mas também para as gerações futuras que se instalaram nessa terra, onde certamente houve uma reedição do pecado original (nus, cruéis e selvagens).

Em certo sentido, a caixa criada por Gustavo Piqueira, Oito Viagens ao Brasil (São Paulo, WMF Martins Fontes/Publicações BBM, 2017), que reúne oito pequenas brochuras contendo diferentes versões/interpretações/projeções das viagens ao Novo Mundo, traduz em imagens, sensações e gestos, essa cicatriz de origem. O impacto foi potencializado com a exposição homônima organizada no Museu da Casa Brasiliana, aberta quando do lançamento da obra. 


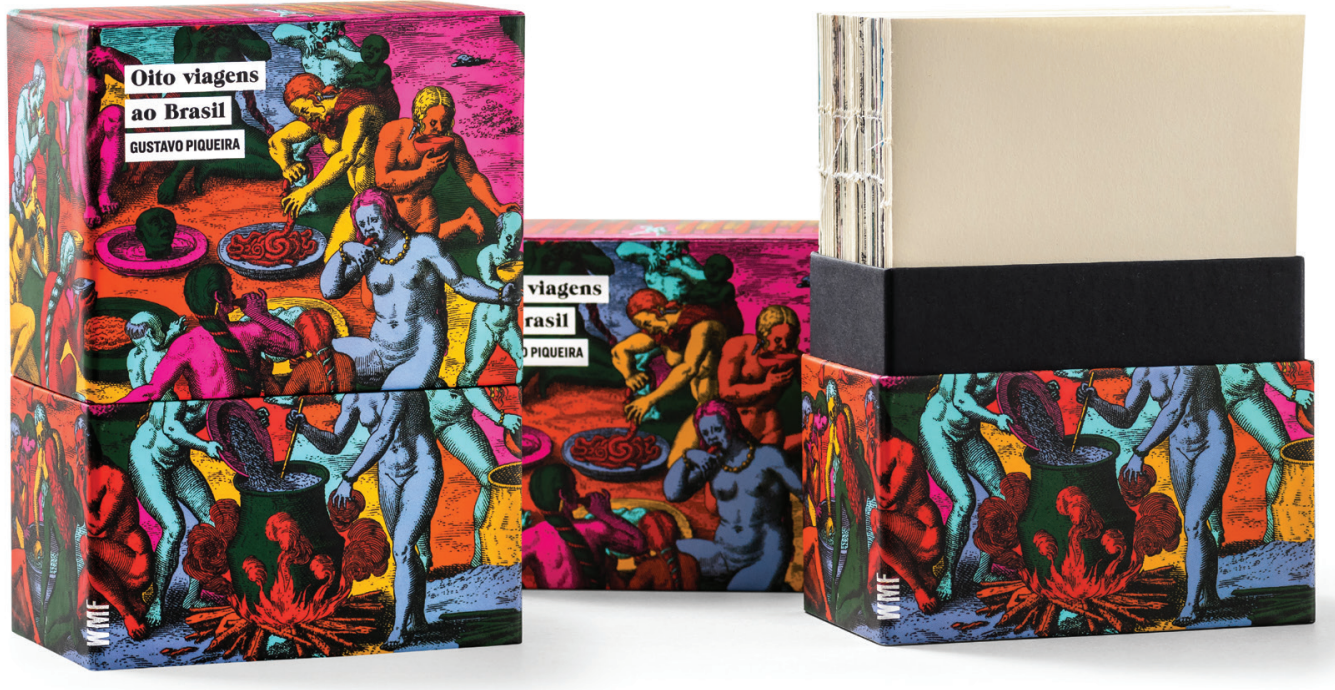

Oito Viagens ao Brasil.

Gustavo Piqueira. São Paulo,

WMF Martins Fontes. Publicações BBM,

2017. ISBN 978-85-469-0163-0,

$18,8 \times 13,2 \times 8 \mathrm{~cm}$ 
A primeira viagem se inicia com um jovem que acaba de perder sua mãe e, do trauma, nasce o desejo da busca por si mesmo. O menino que descobre o seu lugar na escola, nas Copas do Mundo e nas guias de recolhimento dos impostos encontra-se um pouco na obra de Hans Staden, "o primeiro livro sobre o Brasil", como ele mesmo constata (vol. 1, p. 12).

De fato, o registro de Hans Staden compõe um capítulo importante da história das descobertas, a saber, a presença de missionários religiosos - católicos e protestantes - na costa brasileira e, também, de corsários, todos vindos do reino de França. Sabemos que os protagonistas na partilha do Novo Mundo foram Espanha e Portugal, de tal sorte que ingleses e franceses tiveram uma presença marginal nesse primeiro momento. Porém, no que toca ao caso francês, essas viagens se converteram em relatos que deram conta dos povos indígenas, de seus traços, de seus hábitos, num só termo, de sua cultura na América e, em muitos casos, de suas vidas na Europa.

Afonso Arinos de Mello Franco faz um repertório exaustivo de toda essa produção, desde a presença célebre de mais de vinte indígenas que compuseram o décor da festa de entrada do rei Henrique II, em Rouen, em 1550 - cujos registros foram gravados em xilogravura, em bela edição publicada no mesmo ano ${ }^{1}$ - até as notas de Montaigne tiradas de uma entrevista que o célebre ensaísta teria realizado, em 1562, com dois jovens índios levados por Nicolas Durand de Villegaignon para a França. A exemplo do que ocorreu com outros nativos da América, esses jovens foram batizados e viveram entre os franceses ${ }^{2}$.

Os repertórios de viagem que circularam amiúde durante o século XVI não escaparam à percepção de Rabelais, que lhe dá voz em seu Pantagruel (livre IV):

Là je veiz, selon mon advis, Hérodote, Pline, Solin, Beroze, Philostrate, Mela, Strabo et tant d'aultres anticques, plus Albert le Jacobin grand, Pierre Testemoing, Pape Pye Second, Paulle Jovio le vaillant homme, Cadacuist [Cadamosto], Tevault [André Thevet], Jacques Cartier [voyageur qui arrive au Canada en 1534], Haïton Arménien, Marc Paule Vénétien [navigateur qui part à l'Orient, jusqu'à l'Empire Chinois], Ludovic Romain, Pietre Alvarès [Pedro Álvares Cabral] et ne sçay combien d'aultres historiens cachés derrière une pièce de tapisserye, en tapinois escripvant de belles besognes, et tout pour Ouy-Dire ${ }^{3}$.

1. Lors de l'Entrée d'Henri ll à Rouen le 1er Octobre 1550, où Figurent des Brisilians (sic) dans les Scènes Proposées aux Spectateurs. Collection de la Bibliothèque Mazarine - Paris (Rés. 17741, Cat. 65).

2. Cf. Afonso Arinos de Mello Franco, O Índio Brasileiro e a Revolução Francesa, Rio de Janeiro, José Olympio Editora, 1937.

3. François Rabelais, Le quart-livre: Texte Original et Translation en Français Moderne, Paris, Les Éditions du Seuil, 1997. 
Porém, a releitura do jovem Arthurzinho, o personagem que abre as oito viagens de Gustavo Piqueira, será classificada como uma “egotrip melodramática”, pela impiedosa Professora Neide Avaloni, que entra em cena no segundo volume. Em estudo mais denso e escrito em tom professoral, aprendemos sobre as diferentes ilustrações que o relato de Hans Staden recebeu em suas múltiplas edições. Não se trata, apenas, de um problema de representação das descrições, mas também de natureza editorial, ou, no limite no processo de produção e ilustração dos livros e das apropriações das imagens nos primeiros séculos da tipografia. Uma análise fina e ricamente ilustrada se apresenta, por exemplo, quando o autor compara as representações do ritual de antropofagia em Thévet, Léry, Stade e Gândavo (vol. 2, p. 45).

Nos volumes seguintes, as viagens são demarcadas por diálogos e/ ou aproximações: Hans Staden e Theodor de Bry, vol. 3; fLOKOs, vol. 4; Suhelty Souza Hvroldt, vol. 5; Marcão e Hans Staden, vol. 6, talvez o volume em que o pecado de origem se torne flagrante; no vol. 7, Arthur Junior se volta para Theodor de Bry, destacando os requintes artísticos de sua edição; Marcão volta na oitava viagem, sem nenhum requinte artístico, mas, certamente, com a mesma voracidade antropofágica que inspirou algumas vertentes do modernismo brasileiro.

Afinal de contas, não menos pantagruélicas serão as releituras contemporâneas daqueles viajantes-missionários europeus. Sobretudo, aquelas que se fazem sobre Hans Staden, possivelmente em virtude do tom coloquial e "natural" que o autor imprime em suas descrições. Notemos, o que não é menos conhecido, com que força os rituais de antropofagia foram transpostos para a criação brasileira verde e amarela (com ressonâncias europeias).

O Manifesto Pau Brasil (1924), de Oswald de Andrade, constitui uma defesa da poesia nacional, pura, primitiva, sem os vícios da cultura acadêmica. Macunaíma, de Mario de Andrade (1928), montou sua narrativa com base nas lendas indígenas do Amazonas. Mais precisamente, o autor recolhe as histórias do herói mítico Makunaima, compiladas pelo etnólogo alemão Theodor Koch-Grünberg, para o segundo volume de seu Vom Roraima zum Orinoco (1915) ${ }^{4}$. Esses títulos testemunham as transferências de conhecimentos tomadas por uma ciência etnográfica e arqueológica em pleno desenvolvimento, o que diz muito do interesse do Velho Mundo pelas civilizações americanas e da capacidade criadora dos artistas do Novo Mundo. Vemos, aliás, que as referências

4. Apud José de Paula Ramos Jr., Leituras de Macunaíma. Primeira Onda (1928-1936), São Paulo, Edusp/Fapesp, 2012, pp. 20-21. 

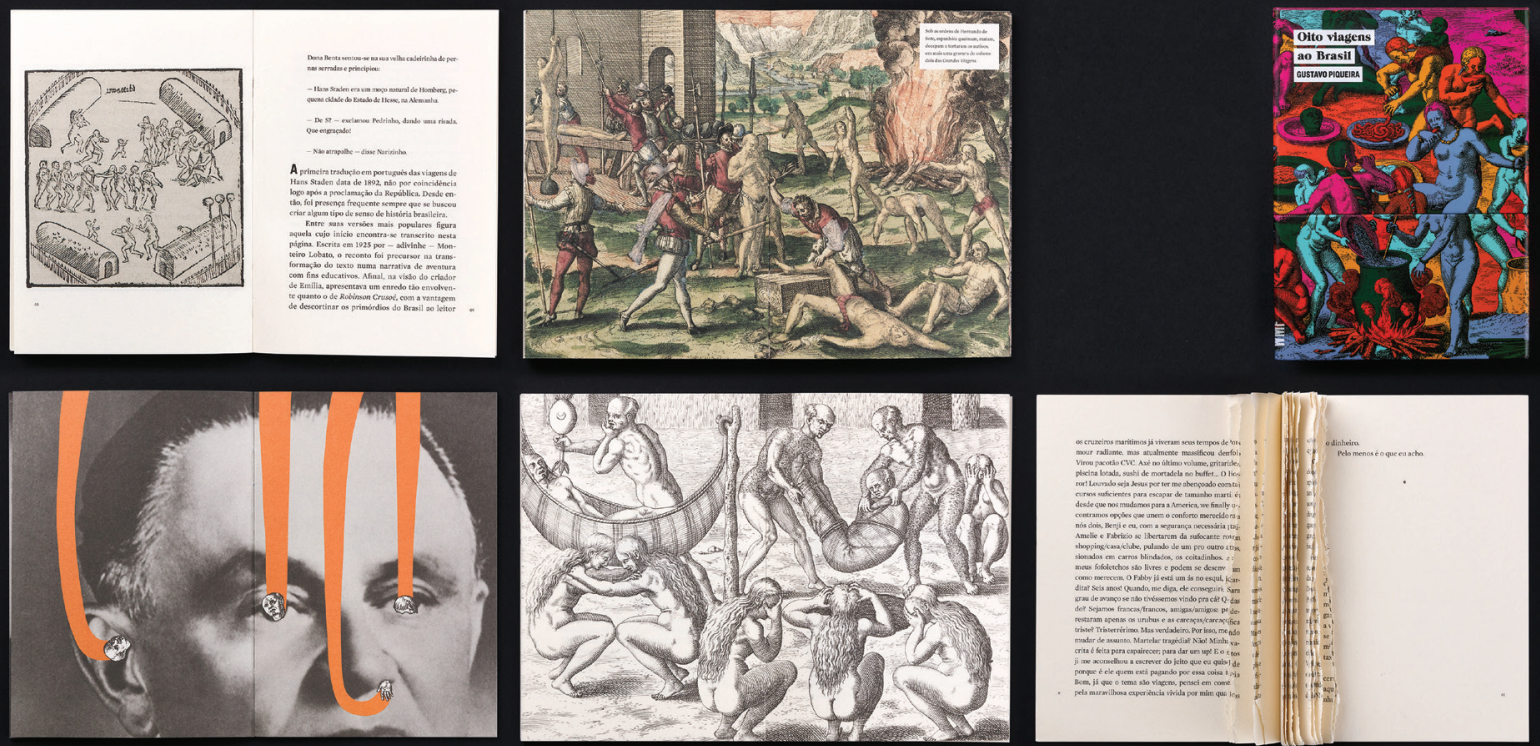

ULTIMAS UNIDADIES

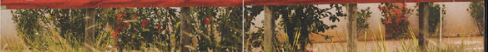
(5)
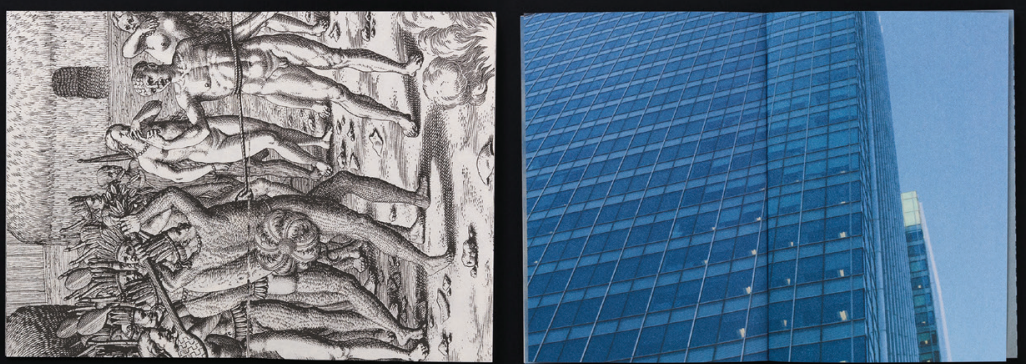
circulam através do Atlântico e se convertem, aqui e lá, em programas, projetos e manifestações que tocam a literatura, mas também as belas artes e as artes aplicadas, como observamos noutro estudo ${ }^{5}$.

Rego Monteiro propõe uma inversão bem significativa desses elementos. É o que conta o autor no início de Quelques Visages de Paris:

Um dia, um chefe selvagem deixando a floresta virgem vem a Paris incógnito, ao final de uma breve estadia, ele retorna com ar blasé, tomado de tantas grandezas, à sua oca (home)... Ele então me confiou suas impressões de Paris, ao mesmo tempo que alguns croquis realizados nos locais, os quais eu reuni sob o título Algumas Imagens de Paris" ${ }^{\text {. }}$

Diferente das travessias realizadas no século XVI, por meio das quais os indígenas eram batizados, aculturados, num só termo, preparados para a vida civilizada (leia-se, europeia), agora o "cacique" fala por si mesmo, chegando a transferir elementos de sua teogonia aos objetos descritos. De um ponto de vista totalmente original, é o índio quem aplica seus traços geométricos nesta espécie de "caderno de viagem”, no qual os monumentos da Cidade Luz são convertidos em... arte guarani!

Mas a antropofagia praticada por Piqueira bebe em outras fontes. Ela escancara não exatamente a força criadora de nosso pecado original, mas, a sua vertente destrutiva. A um país que perde de uma geração para a outra sua memória. Que se engole e que se reinventa a todo instante. Voltando ao início trágico do personagem Arthuzinho, que inicia sua egotrip no primeiro volume, pode-se dizer que ele traduz bem o viés crítico das interpretações que se faz das obras dos viajantes, tanto no que toca o processo gráfico, na perspectiva da História do Livro, mas, também, de suas apropriações, numa perspectiva de longa duração.

Trocando em miúdos, são oito viagens que podem bem ser lidas como oito vertigens de um viajante deslocado no turbilhão de imagens sem memória que invadem nossas cidades.

5. Marisa Midori Deaecto, "Auguste Herborth e o Art Déco Guarany: Diálogos França-Brasil (1920-1930)", Revista uSP, n. 116, 2018.

6. Vicente de Rego Monteiro, Quelques Visages de Paris. Paris, Imprimerie Juan Dura, 1925. Tomamos como fonte o exemplar de Ruy Sousa e Silva, fac-similado e comentado por Jorge Schwartz e traduzido por Regina Salgado Campos (São Paulo, Edusp, 2005). 